\title{
Release of Antioxidants from Biocomposites based on Poly(Lactic Acid) and Durian Rind Cellulose
}

\author{
Patpen Penjumras ${ }^{1}$, Russly Abdul Rahman ${ }^{2,3}$ and Isara Wattananapakasem ${ }^{1}$ \\ ${ }^{1}$ Program of Food Science and Technology, Maejo University-Phrae Campus \\ 54140 Phrae Province, Thailand \\ ${ }^{2}$ Department of Process and Food Engineering, Faculty of Engineering, Universiti Putra Malaysia \\ 43400 UPM Serdang, Selangor, Malaysia \\ ${ }^{3}$ Department of Food Technology, Faculty of Food and Science, Universiti Putra Malaysia \\ 43400 UPM Serdang, Selangor, Malaysia
}

\begin{abstract}
The migration of antioxidants including $\alpha$-tocopherol and butylated hydroxytoluene (BHT) from biocomposites based on poly(lactic acid) (PLA) and durian rind cellulose into food simulants were investigated. The biocomposites materials containing $1 \% \mathrm{w} / \mathrm{w}$ antioxidant were blended using Brabender internal mixer followed by hot press machine and were then placed in contact with $95 \%$ and $50 \%$ ethanol at $27^{\circ} \mathrm{C}$ and $37^{\circ} \mathrm{C}$. Released antioxidants were measured by UV-spectroscopy for 45 days. First-order kinetics and diffusion modeling were used to describe the release behavior. The release rates of antioxidant into food simulants displayed the first-order rate constant and diffusion coefficient of $10^{-6} \mathrm{~S}^{-1}$ and $10^{-10} \mathrm{~m}^{2} \mathrm{~s}^{-1}$, respectively. The higher diffusion coefficient in each case indicated the faster release rate. The material containing BHT generated the faster release into $95 \%$ ethanol than $50 \%$ ethanol meanwhile $\alpha$-tocopherol released into $50 \%$ ethanol faster than $50 \%$ ethanol. For both simulants, BHT presented higher release rate than $\alpha$-tocopherol. For all conditions, the antioxidants released at $37^{\circ} \mathrm{C}$ faster than $27^{\circ} \mathrm{C}$. Therefore, the release rate of antioxidant from the material was dependent on the type of antioxidant incorporated, food simulant and storage temperature. The release behavior of antioxidant can be used for creating antioxidant active packaging material to produce safer foods.
\end{abstract}

Keywords: poly (lactic acid), cellulose, active packaging, $\alpha$-tocopherol, butylated hydroxytoluene, migration

\section{Introduction}

Recently, consumers are increasingly demanding mildly preserved convenience foods that have better freshlike qualities. In addition, changes in retail and distribution practices such as centralization of activities, new trends and inter-nationalization of markets resulting in increased distribution distances meanwhile traditional packaging concepts are limited in their ability to prolong the shelf-life of food products [1]. Therefore, the consumer way acts as driving forces for the development of new and improved packaging concepts that extend shelf-life to the food packaging industry. Active packaging is a new concept of food packaging by continuous releasing active component such as antioxidant, antimicrobial, flavor, etc. Its interaction between the package, the food and the environment, can prolong shelf-life of foods, provide higher protection of flavors and lower usage of additives and preservatives in food formulations while maintaining the quality of product. Limitations of direct addition of antioxidants to food include specific limit of activity due to their participation in complex reactions in food system [2]. Oxidation is one of the main factors of food deteriorations. The products of oxidation generate off-flavor, color change, and nutritional losses of lipid food. Antioxidants are normally used to inhibit the oxidation by combination of scavenging free radicals, chelating pro-oxidative metals, quenching 
singlet oxygen, and inactivating lipoxygenase [3]. However, addition of antioxidant directly may induce the risk of pro-oxidation reaction which decreases food quality [4]. Antioxidant active packaging becomes the alternative way to prolong shelf life of lipid product. In recent year, creating of antioxidant active packaging with control release ability via using various types of antioxidant, polymer, release modifying agent has gain extra attention. The objectives of this study were to characterize the release behavior and to calculate the release parameters of antioxidants including BHT and $\alpha$-tocopherol with $1 \% \mathrm{w} / \mathrm{w}$ from biocomposites based on PLA and durian rind cellulose. The effect of the material added with antioxidant on the stability of edible oil during storage was also investigated.

\section{Material and Method}

\subsection{Materials And Chemicals}

Durian rinds (cultivar D159 Monthong) were collected from Phatthalung Province, Thailand. Poly(lactic acid) (PLA) resin (Ingeo biopolymer 2003D food packaging-grade with $>98 \%$ purity; specific gravity of 1.24 and $6 \mathrm{~g} / 10$ min melting flow index at $210{ }^{\circ} \mathrm{C}$ ) was purchased from Natureworks (USA). Reagent-grade of glacial acetic acid $\left(\mathrm{CH}_{3} \mathrm{COOH}\right)$ and sodium hydroxide $(\mathrm{NaOH})$, and technical-grade of $80 \%$ purity sodium chlorite $\left(\mathrm{NaClO}_{2}\right)$ and $99 \%$ purity 3-aminopropyltriethoxysilane (APS) were supplied by Fisher Chemicals Sdn Bhd. (Malaysia). Tocopherol R\&M® (Dl- $\alpha$-tocopherol with 97\% purity; $\mathrm{Mw}=430.72 \mathrm{~g} / \mathrm{mol}$ ) and BHT (Butylated hydroxytoluene with $99 \%$ purity; $\mathrm{Mw}=220.36 \mathrm{~g} / \mathrm{mol}$, melting range $68-90{ }^{\circ} \mathrm{C} \mathrm{R \& M}$ Marketing Essex UK.) were purchased from Lab Science Engineering Sdn. Bhd. (Malaysia). Absolute ethanol, methanol, acetic acid, potassium iodide, sodium thiosulfate, chloroform and hydrochloric acid Labscan®; starch Ajax®; 2thiobarbituric acid and trichloroacetic acid Merck®; 2,2-diphenyl-1-picrylhydrazyl free radical Sigma ${ }^{\circledR}$ and Malonaldyhyde-bis (dimethyl acetal) were purchased from Union Science Thailand.

\subsection{Extraction of Cellulose From Durian Rind}

Durian rind cellulose was extracted using a two steps refer to [5]. Firstly, holocellulose was prepared using chlorination method (ASTM D1104). Secondly, the holocellulose was converted to cellulose by mercerization method (ASTM D1103) in order to activate the hydroxyl groups of the cellulose. Then, the extracted cellulose was treated using silane coupling agent according to [6] with slight modification.

\subsection{Preparation Of Antioxidant Packaging Material}

The biocomposites-antioxidant materials were prepared using an internal mixer. For each material, $1 \% \mathrm{w} / \mathrm{w}$ of $\alpha$-tocopherol (AT) and butylated hydroxytoluene (BHT) was added to 35:65 w/w mixture of cellulose-PLA. The mixture was then blended using an internal mixer (Brabender Plastograph EC, Germany) at a 50 rpm screw speed with $165^{\circ} \mathrm{C}$ for $15 \mathrm{~min}$. To avoid pores' formation, the biocomposites were dried in a convection oven at $80{ }^{\circ} \mathrm{C}$ for $16 \mathrm{~h}$. Next, the moulded sheets were then prepared using a hot press machine at $160{ }^{\circ} \mathrm{C}$ with 5 min of preheating and 5 min of pressing, followed by 2 min of cooling according to [7].

\subsection{Release Test}

A study of the release of active compounds from the material was carried out by determining the specific migration from the polymer into the different food simulants specified in European law (Commission Directive 2007/19/EC, 2007). For current study, the simulants included 95\% ethanol as fatty foodstuffs and 50\% ethanol as high alcohol containing products and milk and dairy products. Migration studies were conducted according to [8] with slight modification. Double-sided, total immersion migration tests were performed as follow: a $3 \mathrm{~cm}^{2}$ piece of each plastic sample and $5 \mathrm{~mL}$ of the simulant were placed in test tubes covered with aluminum foil to protect the contents from light. The test tube containing antioxidant materials were placed in an incubator for $37{ }^{\circ} \mathrm{C}$ and in dark room for $27^{\circ} \mathrm{C}$, respectively. To minimize mass-transfer resistance of antioxidants from the materials, the tubes were shook manually two times a day. At first 9 days, test tube was opened every day and the concentration of the antioxidant in the simulants was analyzed by DPPH method. Then, test tube was opened at 3 days intervals over the period of 45 days $(1,080 \mathrm{~h})$. The radical scavenging activity of biocompositesantioxidant material was measured using the stable radical 2,2 -diphenyl-1-picrylhydrazyl (DPPH) according to 
[9]. The control was obtained without food simulant. The mixture was vortexed vigorously and left for 30 min at room temperature in the dark. The bleaching rate of a stable DPPH was monitored at a characteristic wavelength in the presence of the sample. In its radical form, DPPH absorbs at $517 \mathrm{~nm}$ but, upon reduction by an antioxidant or a radical compound, its absorption decreases. The percentage inhibition value was calculated as formula (1)

$$
I(\%)=\frac{[\text { abs }(\text { control })-\text { abs }(\text { sample })]}{\text { abs }(\text { sample })} \times 100
$$

Using a calibrated curve of concentration of antioxidant ( $\alpha$-tocopherol and BHT) vs. I (\%), the results can easily be expressed as the equivalent $\alpha$ - tocopherol and BHT concentration.

\subsection{Overall Kinetics Analysis}

The release of the antioxidant into the food simulant was initially analyzed for its fit to a first order kinetics model as formula (2) [10].

$$
\ln \left(1-\frac{\mathrm{Mt}}{\mathrm{M} \infty}\right)=-k t
$$

Where $\mathrm{M}_{\mathrm{t}}$ is amount of antioxidant released from materials at time, $\mathrm{M}_{\alpha}$ is amount of antioxidant released from materials at equilibrium $(\mathrm{t}=\alpha)$ and $k$ is the first-order rate constant.

\subsection{Determination Of Diffusion Model}

The apparent diffusion coefficients (D) of antioxidant were determined from the release versus time. For short time $\left(M_{t} / M_{\alpha}<2 / 3\right)$, it can be simplified to the following formula (3) for calculation of D [3].

$$
\frac{\mathrm{Mt}}{\mathrm{M} \infty}=4\left(\frac{D t}{\pi L^{2}}\right)^{1 / 2}
$$

Where $\mathrm{M}_{\mathrm{t}}$ is amount of antioxidant released from materials at time, $\mathrm{M}_{\alpha}$ is amount of antioxidant released from materials at equilibrium $(\mathrm{t}=\alpha)$ and $\mathrm{L}$ is $0.5 \mathrm{~mm}$ thickness of material.

\subsection{Stability of Edible Oil Analysis}

Oxidative status analysis was carried out similar with release test. The biocomposites material was immersed in palm oil instead of ethanol solution. At 3 days intervals, test tube was opened and both the primary oxidation products and the secondary ones were monitored over the storage period, by means of the peroxide value and TBARS indices, respectively. A control batch (palm oil without antioxidant added material) was also investigated.

The peroxide value (PV), expressed as meq oxygen $/ \mathrm{kg}$ fat was determined refer to [11] according to method Cd 8-53 (AOCS 1998) of the American Oil Chemists' Society (AOCS). Approximately $2 \mathrm{~g}$ of palm oil was weighted into a 250 Erlenmeyer flask and $30 \mathrm{~mL}$ of mixture of acetic acid/chloroform (3:2 v/v) was added, the contents were then stirred continuously in order to completely dissolve the palm oil. A solution of $1 \mathrm{~mL}$ potassium iodide (KI) was added and the mixture was shook and the flask was allowed to stand for 1 min in dark condition. After that, $30 \mathrm{~mL}$ distilled water was added and titrated against $0.002 \mathrm{~N}$ sodium thiosulfate, with 0.5 $\mathrm{mL}$ of $1 \%$ starch as an indicator. The blank was determined by titration of the sample not containing. The PV (meq $\mathrm{O}_{2} \mathrm{~kg} \mathrm{oil}^{-1}$ ) was calculated as formula (4).

$$
P V=\frac{(S-B) \times N \times 1,000}{W}
$$

Where $\mathrm{S}$ is the volume of sodium thiosulfate consumed during titration of the sample $(\mathrm{mL})$, B is the volume consumed in evaluation of the blank $(\mathrm{mL}), \mathrm{N}$ is the normality of the sodium thiosulfate solution and $\mathrm{W}$ is the weight of palm oil in gram.

Thiobarbituric acid-reactive substances (TBARS) were determined according to [12] by dissolving $0.5 \mathrm{~g}$ oil in $2.5 \mathrm{~mL}$ TBARS solution $(0.0375 \mathrm{~g}$ thiobarbituric acid mixed with $15 \mathrm{~g}$ trichloroacetic acid and $0.875 \mathrm{~mL}$ of $0.25 \mathrm{M}$ hydrochloric acid which adjusted to $100 \mathrm{~mL}$ using distilled water). Sample was mixed for $2 \mathrm{~min}$, and then incubated in water bath at $95-100^{\circ} \mathrm{C}$ for $10 \mathrm{~min}$. Sample was then cooled and centrifuged for $20 \mathrm{~min}$ at $3,600 \times \mathrm{g}$. The intensity of color correlated with the quantity of TBARS in oxidized oil was detected at $532 \mathrm{~nm}$ 
using spectrophotometer (Thermo Scientific UUA-161514 Model Helios). The results express in milligrams per kilogram oil using malonaldehyde-bis as the standard.

\section{Results and Discussion}

\subsection{Release Of Antioxidants Into Simulants}

For a better understanding of antioxidant release behaviors, all the release graphs are presented as the ratio of amount of antioxidant released from materials at time $\left(\mathrm{M}_{\mathrm{t}}\right)$ divided by amount of antioxidant released from materials at equilibrium $\left(\mathrm{M}_{\alpha}\right)$. The release of $1 \% \mathrm{w} / \mathrm{w}$ antioxidants including $\alpha$-tocopherol (AT) and BHT from biocomposites into two food simulants $(50 \%$ and $95 \%$ ethanol in water) at two temperatures $\left(27^{\circ} \mathrm{C}\right.$ and $\left.37^{\circ} \mathrm{C}\right)$ shows in Fig 1. The first-order kinetics and diffusion modeling were used to describe the release and the results present in Table 1 and 2.
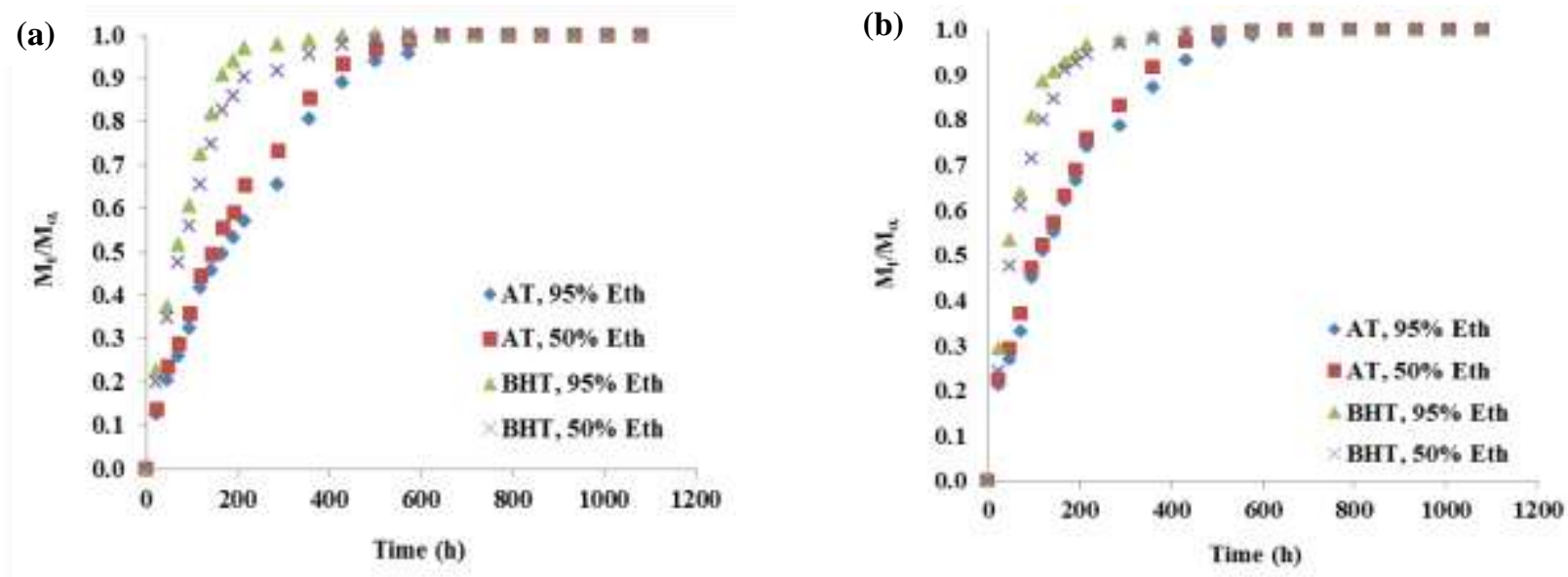

Fig. 1: Antioxidant release rate $\left(\mathrm{M}_{\mathrm{t}} / \mathrm{M}_{\alpha}\right)$ into ethanol at (a) $27{ }^{\circ} \mathrm{C}$ and (b) $37{ }^{\circ} \mathrm{C}$

TABLE I: The First-order Rate Constant $\left(\mathrm{k} \times 10^{-6}, \mathrm{~S}^{-1}\right)$ of Antioxidant from Material into Food Simulant

\begin{tabular}{llclc}
\hline \hline Antioxidant & \multicolumn{2}{c}{$27^{\circ} \mathrm{C}$} & \multicolumn{2}{c}{$37^{\circ} \mathrm{C}$} \\
\hline AT & $95 \%$ Ethanol & $50 \%$ Ethanol & $95 \%$ Ethanol & $50 \%$ Ethanol \\
BHT & $1.967 \pm 0.017$ & $2.308 \pm 0.034$ & $2.263 \pm 0.094$ & $2.692 \pm 0.124$ \\
\hline \hline
\end{tabular}

TABLE II: D Coefficient $\left(\times 10^{-10}, \mathrm{~m}^{2} \mathrm{~S}^{-1}\right)$ of Antioxidant from Material into Food Simulant

\begin{tabular}{lllll}
\hline \hline Antioxidant & \multicolumn{2}{c}{$27{ }^{\circ} \mathrm{C}$} & $37{ }^{\circ} \mathrm{C}$ \\
\hline & $95 \%$ Ethanol & $50 \%$ Ethanol & $95 \%$ Ethanol & $50 \%$ Ethanol \\
AT & $3.344 \pm 0.050$ & $4.132 \pm 0.065$ & $4.666 \pm 0.043$ & $4.668 \pm 0.013$ \\
BHT & $7.518 \pm 0.044$ & $7.141 \pm 0.034$ & $11.382 \pm 0.068$ & $10.036 \pm 0.025$ \\
\hline \hline
\end{tabular}

Basically, antioxidants with higher Log P (higher lipophilicity) somehow permit their release into highly apolar simulants. Therefore, $\alpha$-tocopherol was expected to provide higher release rate into $95 \%$ ethanol than BHT due to its Log P of 12.1 compared to lower Log P 4.1 of BHT [2]. However, the result was observed that the release rate of $\alpha$-tocopherol was slower than BHT for all conditions as Fig 1. This can be associated with $\alpha$-tocopherol has higher molecular weight of $430.72 \mathrm{~g} / \mathrm{mol}$ than BHT which has molecular weight of 220.54 $\mathrm{g} / \mathrm{mol}$ then leading a low mobility of the molecule in biocomposites structure. Moreover, the contact of biocomposites with $50 \%$ ethanol which higher polarity condition affecting water in simulant absorbed by cellulose then resulting structure weakness. The pore's formation was then occurred and contributed release of high molecular weight of $\alpha$-tocopherol. 
Moreover, the lower of release rate of $\alpha$-tocopherol related to the low vapor pressure of $\alpha$-tocopherol (70 $\mathrm{mm} \mathrm{Hg}$ at $\left.200^{\circ} \mathrm{C}\right)$ compared to BHT $\left(140 \mathrm{~mm} \mathrm{Hg}\right.$ at $\left.200^{\circ} \mathrm{C}\right)$ [13]. The results also showed that an increase in release rate of antioxidant can be observed when the temperature increase which can be related to an increase in vibration and motion of polymer chain as the temperature increase, resulting in the migration movement through the amorphous zones of polymer [14]. The maximum percentage releases of antioxidants at equilibrium time are displayed in Table 3.

TABLE III: The First-order Rate Constant $\left(\mathrm{k} \times 10^{-6}, \mathrm{~S}^{-1}\right)$ of Antioxidant from Material into Food Simulant

\begin{tabular}{lllll}
\hline \hline Antioxidant & \multicolumn{2}{c}{$27{ }^{\circ} \mathrm{C}$} & \multicolumn{2}{c}{$37^{\circ} \mathrm{C}$} \\
\hline & $95 \%$ Ethanol & $50 \%$ Ethanol & $95 \%$ Ethanol & $50 \%$ Ethanol \\
AT & $61.22 \pm 0.34(720)$ & $65.14 \pm 0.35(648)$ & $65.24 \pm 0.60(648)$ & $68.29 \pm 0.35(576)$ \\
BHT & $81.73 \pm 0.97(504)$ & $79.55 \pm 0.56(576)$ & $92.06 \pm 0.28(432)$ & $88.05 \pm 0.14(540)$ \\
\hline \hline
\end{tabular}

The results were found that the maximum amount at equilibrium time of BHT was higher than $\alpha$-tocopherol for each condition due to the interaction between some of $\alpha$-tocopherol and PLA. PLA is polyester with esterified carboxylic groups that may interact with hydroxide group of $\alpha$-tocopherol [11]. Therefore, it can be concluded that $\alpha$-tocopherol is not suitable for active packaging material due to high retention.

\subsection{Effect of the Material Added with Antioxidant on the Stability of Edible Oil}

This experiment was performed under the same conditions as those used for the release test except palm oil was used instead of simulant. Evaluating lipid oxidation is complex due to the oxidative breakdown products are unstable during storage therefore both the primary oxidation products and the secondary ones were monitored over the storage period, by means of the peroxide value (PV) and TBARS indices, respectively. A control batch was palm oil without antioxidant added material. The effect of the material added with antioxidant on peroxide value displays as Fig. 2.
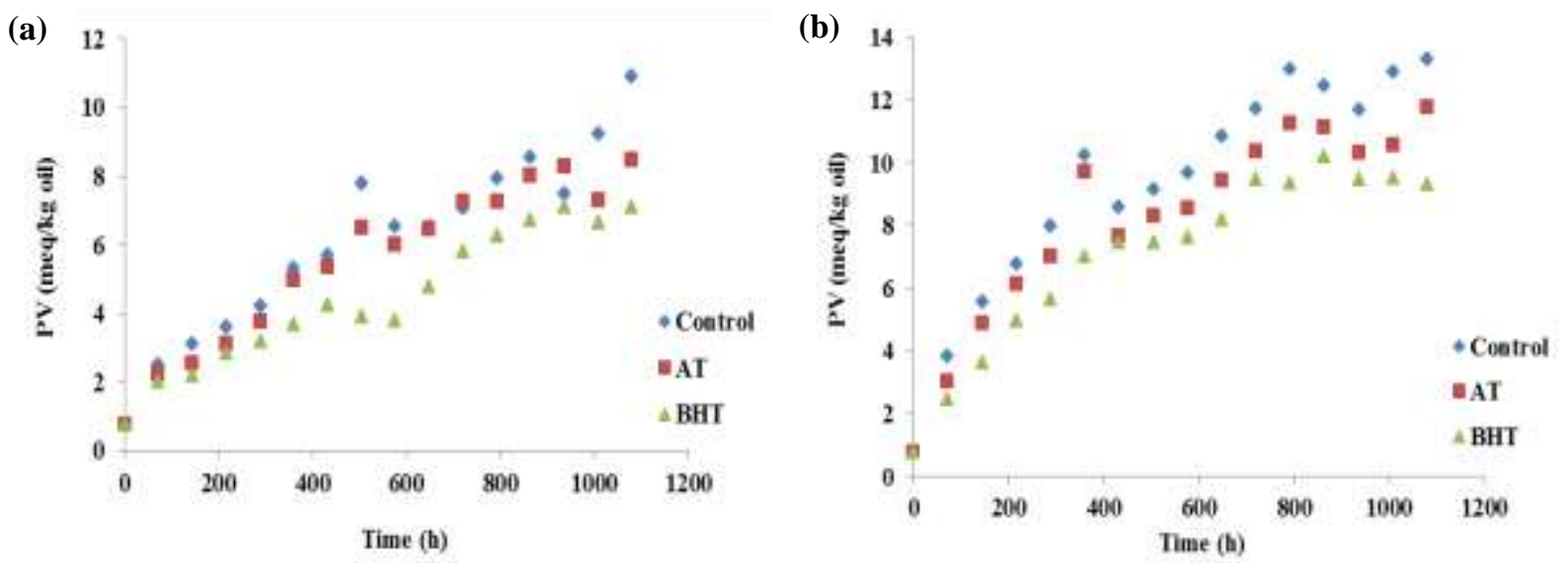

Fig. 2: Change in Peroxide Value in Palm Oil Contact with Antioxidant Active Material Store at (A) $27^{\circ} \mathrm{C}$ and (B) $37{ }^{\circ} \mathrm{C}$

The results show that the fresh palm oil had PV of $0.77 \pm 0.10 \mathrm{meq} / \mathrm{kg}$ oil. The PV for all conditions tends to increase during early stage of oxidation, when the rate of formation of hydroperoxides is higher than rate of decomposition. A maximum is reached then decreases as a result of the lower availibity of substrate and instability of peroxide molecules, which leads to lower speed formation with respect to the rate of decomposition [11]. The sudden drops of PV in each condition because of hydroperoxides are transitory and rapidly break down into secondary products of oxidation, such as epoxides, hydroxyls, aldehydes, ketones, alcohol, and hydrocarbons [16]. In control sample which was the palm oil without contact to antioxidant material, there was a sharp increase in PV especially the sample at higher storage temperature of $37^{\circ} \mathrm{C}$. At $27^{\circ} \mathrm{C}$, a typical oxidation graph with maximum PV value of $10.90 \mathrm{meq} / \mathrm{kg}$ oil at $45 \mathrm{~d}(1,080 \mathrm{~h})$ of storage which was higher than the maximum level accepted by Codex Alimentarius in refined vegetable oils. Meanwhile, the control sample at $37{ }^{\circ} \mathrm{C}$ reached PV value of $10.84 \mathrm{meq} / \mathrm{kgoil}$ at $27 \mathrm{~d}(648 \mathrm{~h})$ and tended to increase during storage until had 
maximum PV value of $13.29 \mathrm{meq} / \mathrm{kg}$ oil at $45 \mathrm{~d}(1,080 \mathrm{~h})$. The similar trend of oxidation in stabilizing oils from smoked salmon was found [16]. The storage temperature at higher of $35^{\circ} \mathrm{C}$ showed the higher PV value compared to $4^{\circ} \mathrm{C}$ due to more products of lipid oxidation were produced.

Generally, antioxidants or phenolic substances are used to inhibit the mechanism of lipid auto-oxidation of free radicals. Antioxidant act as free radical acceptors, then terminate the oxidation at the initial stage and also prevent further formation of new radicals in the oxidation process [17]. The compound formed in this reaction is not stable and degrade into other compounds which are cause of loss of taste or smell. The TBARS assay is normally used to monitor oxidation by screening for aldehydes and other relatively polar or charged reaction intermediates [16]. Changes in TBARS in palm oil in contact with antioxidant active material during storage present as Fig. 3.
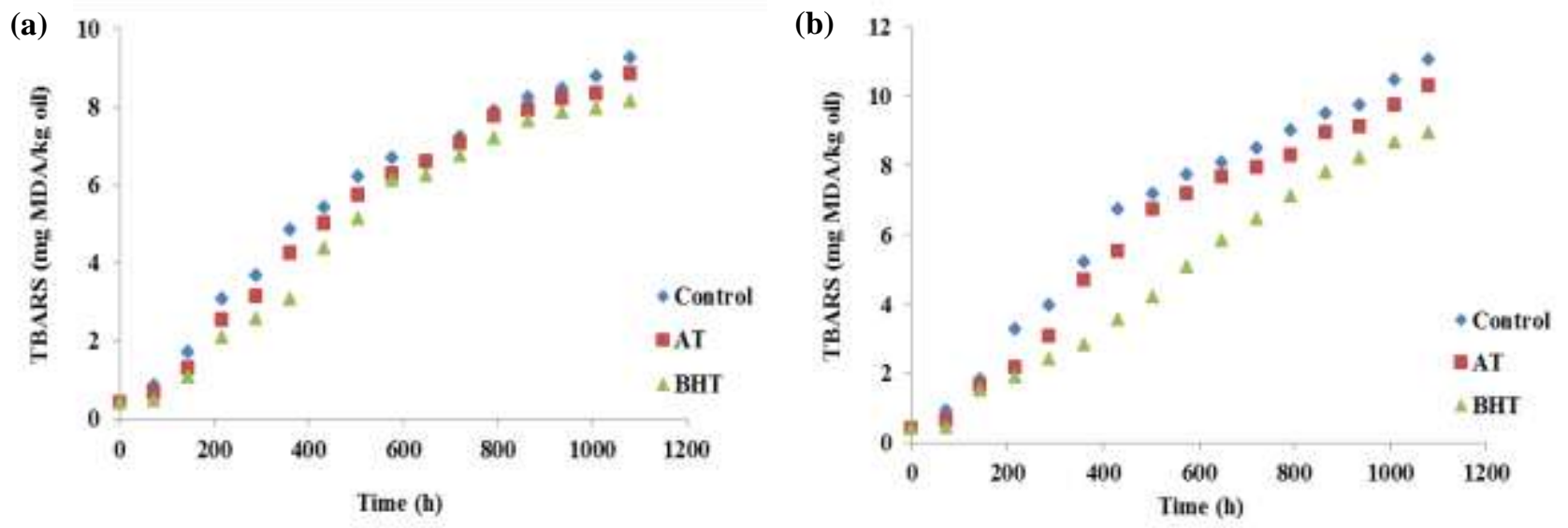

Fig. 3: Change in TBARS in palm oil contact with antioxidant active material store at (a) $27^{\circ} \mathrm{C}$ and (b) $37^{\circ} \mathrm{C}$

The results represent increase of TBARS during storage. Nevertheless, peroxide degradation of sample contact with antioxidant active material was delayed. This was an indication of the radical-scavenging activity of antioxidants from the active materials, which was also confirmed by a decrease of aldehyde accumulation.

\section{Conclusion}

The important factors affecting the control and release mechanism of antioxidant are antioxidant physicochemical properties, storage temperature and migrant solubility in the simulant. Generally, smaller molecular size can be released faster than greater size. Therefore, BHT had higher release rate than $\alpha$-tocopherol. At higher temperature resulting release rate to be increased. BHT released faster into $95 \%$ ethanol, meanwhile $\alpha$-tocopherol released faster into 50\% ethanol. The faster release of antioxidant from each condition contributed to inhibition of lipid oxidation which indicating by decrease of PV and TBARS. From this study can be concluded that BHT had higher effectiveness to be antioxidant in active packaging. The release behavior of antioxidant can be used to create antioxidant-active packaging material and also alternative approach to reduce the amounts of directly added antioxidants in foods to provide safer foods.

\section{Acknowledgements}

I am sincerely grateful for my home university; Maejo University-Phrae Campus. I also acknowledge Institute of Tropical Forestry and Forest Products, Universiti Putra Malaysia for laboratory equipment and all technical staff for their support.

\section{References}

[1] L. Vermeiren, F. Devlieghere, M. van Beest, N. de Kruijf and J. Debevere, "Developments in the active packaging of foods," Trends in Food Science \& Technology, vol. 10, pp. 77-86, 1999.

https://doi.org/10.1016/S0924-2244(99)00032-1 
[2] M. Jamshidian, E.A. Tehrany and S. Desobry, "Release of synthetic phenolic antioxidants from extruded poly lactic acid (PLA) film," Food Control, vol. 28, pp. 445-455, 2012.

https://doi.org/10.1016/j.foodcont.2012.05.005

[3] M. Jamshidian, E.A. Tehrany and S. Desobry, "Antioxidant release from solvent cast PLA film: investigation of PLA antioxidant-active packaging,” Food Bioprocess Technology, vol. 6, pp. 1450-1463, 2013.

https://doi.org/10.1007/s11947-012-0830-9

[4] A.Z. Graciano-Verdugo, H. Soto-Valdez, E. Peralta, P. Cruz-Zárate, A.R. Islas-Rubio, S. Sánchez-Valdes, A. Sánchez-Escalante, N. González-Méndez and H. González-Ríos, "Migration of $\alpha$-tocopherol from LDPE films to corn oil and its effect on the oxidative stability," Food Research International, vol. 43, pp. 1073-1078, 2010.

https://doi.org/10.1016/j.foodres.2010.01.019

[5] I.S.M.A. Tawakkal, R.A. Talib, K. Abdan and N.L. Chin, "Mechanical and physical properties of kenaf-derived cellulose (KDC)-filled polylactic acid (PLA)," BioResources, vol. 7, pp. 1643-1655, 2012.

https://doi.org/10.15376/biores.7.2.1643-1655

[6] M.S. Huda, LT. Drzal, A.K. Mohanty and M. Misra, "Effect of fiber surface-treatments on the properties of laminated biocomposites from poly(lactic acid) (PLA) and kenaf fibers," Composites Science and Technology, vol. 68, pp. 424432, 2008

https://doi.org/10.1016/j.compscitech.2007.06.022.

[7] P. Penjumras, R. Abdul Rahman R, R.A. Talib and K. Abdan, "Effect of silane coupling agent on properties of biocomposites based on poly(lactic acid) and durian rind cellulose," IOP Conf. Series: Materials Science and Engineering, vol. 137, pp. 1-13, 2016.

[8] C. López-de-Dicastillo, J. Gómez-Estaca, R. Catalá, R. Gavara and P. Hernández-Muñoz, "Active antioxidant packaging films: Development and effect on lipid stability of brined sardines," Food Chemistry, vol. 131, pp. 13761384, 2012.

https://doi.org/10.1016/j.foodchem.2011.10.002

[9] J.T. Martins, M.A. Cerqueira and A.A. Vicente, "Influence of $\alpha$-tocopherol on physicochemical properties of chitosanbased films," Food Hydrocolloids, vol. 27, pp. 220-227, 2012. https://doi.org/10.1016/j.foodhyd.2011.06.011

[10] I.S.M.A. Tawakkal, M.J. Cran and S.W. Bigger, "Release of thymol from poly(lactic acid) -based antimicrobial films containing kenaf fibres as natural filler," LWT-Food Science and Technology, vol. 66, pp. 629-637, 2016.

https://doi.org/10.1016/j.Iwt.2015.11.011

[11] D.A. Pereira de Abreu, P. Paseiro Losada, J. Maroto and J.M. Cruz, "Evaluation of the effectiveness of a new active packaging film containing natural antioxidants (from barley husks) that retard lipid damage in frozen Atlantic salmon (Salmo salar L.)," Food Research International, vol. 43, pp. 1277-1282, 2010.

https://doi.org/10.1016/j.foodres.2010.03.019

[12] J.A. Buege and S.D. Aust, "Microsomal lipid peroxidation," in Methods in Enzymology, S. Fleischer and L. Packer, Ed. New York: Academic Press, pp. 303-310, 1978.

[13] D. Granda-Restrepo, E. Peralta, R. Troncoso-Rojas and H. Soto-Valdez, "Release of antioxidants from co-extruded active packaging developed for whole milk powder," International Dairy Journal, vol. 19, pp. 481-488, 2009.

https://doi.org/10.1016/j.idairyj.2009.01.002

[14] M.M. Castro López, S. Dopico García, A.A Pernas, J.M. López Vilariño and M.V. González Rodríguez, "Effect of PPG-PEG-PPG on the tocopherol-controlled release from films intended for food-packaging applications," Journal of Agricultural and Food Chemistry, vol. 60, pp. 8163-8170, 2012.

https://doi.org/10.1021/jf301442p 
[15] F. Manzanarez-López, H. Soto-Valdez, R. Auras and E. Peralta, "Release of $\alpha$-tocopherol from poly(lactic acid) films, and its effect on the oxidative stability of soybean oil,"Journal of Food Engineering, vol. 104, pp. 508-517, 2011. https://doi.org/10.1016/j.jfoodeng.2010.12.029

[16] C.K. Bower, K.A. Hietala, A.C.M. Oliveira and T.H. Wu, "Stabilizing Oils from Smoked Pink Salmon (Oncorhynchus gorbuscha)," Journal of Food Science, vol. 74, pp. C248-C257, 2009. https://doi.org/10.1111/j.1750-3841.2009.01099.x

[17] A. OSullivan, A. Mayr, N.B. Shaw, S.C. Murphy and J.P. Kerry, "Use of natural antioxidants to stabilize fish oil systems," Journal of Aquatic Food Product Technology, vol. 14, pp. 75-94, 2005.

https://doi.org/10.1300/J030v14n03_06 